\title{
Calculation of full-pattern neutron time-of-flight (TOF) powder diffraction patterns - CORRIGENDUM
}

\author{
J. Faber
}

doi: https://doi.org/10.1017/S0885715617000914, Published by Cambridge University Press, 31 August 2017

In Faber (2017), a key word was published incorrectly, appearing as "neuron".

The key word should appear as "neutron".
Additionally, the chemical formula for NAC is incorrect in the abstract. The correct formula is $\mathrm{Na}_{2} \mathrm{Ca}_{3} \mathrm{Al}_{2} \mathrm{~F}_{14}$.

The author apologizes for the errors.

Faber, J. (2017). "Calculation of full-pattern neutron time-of-flight (TOF) powder diffraction patterns," Powder Diffr. 32, 228-236. doi:10.1017/ S0885715617000914. 